Article

\title{
Supraoptimal Cytokinin Content Inhibits Rice Seminal Root Growth by Reducing Root Meristem Size and Cell Length via Increased Ethylene Content
}

\author{
Xiao Zou, Junwei Shao, Qi Wang, Peisai Chen, Yanchun Zhu and Changxi Yin * (B) \\ MOA Key Laboratory of Crop Ecophysiology and Farming System in the Middle Reaches of the Yangtze River, \\ College of Plant Science and Technology, Huazhong Agricultural University, Wuhan 430062, China; \\ zouxiao@webmail.hzau.edu.cn (X.Z.); hzauphytohormone@163.com (J.S.); wqi@webmail.hzau.edu.cn (Q.W.); \\ peisaichen@163.com (P.C.); zhuyanchun@webmail.hzau.edu.cn (Y.Z.) \\ * Correspondence: yinchangxi@mail.hzau.edu.cn; Tel.: +86-278-728-2130
}

Received: 30 October 2018; Accepted: 12 December 2018; Published: 14 December 2018

\begin{abstract}
Cytokinins (CKs), a class of phytohormone, regulate root growth in a dose-dependent manner. A certain threshold content of CK is required for rapid root growth, but supraoptimal CK content inhibits root growth, and the mechanism of this inhibition remains unclear in rice. In this study, treatments of lovastatin (an inhibitor of CK biosynthesis) and kinetin (KT; a synthetic CK) were found to inhibit rice seminal root growth in a dose-dependent manner, suggesting that endogenous CK content is optimal for rapid growth of the seminal root in rice. KT treatment strongly increased ethylene level by upregulating the transcription of ethylene biosynthesis genes. Ethylene produced in response to exogenous $\mathrm{KT}$ inhibited rice seminal root growth by reducing meristem size via upregulation of OsIAA3 transcription and reduced cell length by downregulating transcription of cell elongation-related genes. Moreover, the effects of KT treatment on rice seminal root growth, root meristem size and cell length were rescued by treatment with aminoethoxyvinylglycine (an inhibitor of ethylene biosynthesis), which restored ethylene level and transcription levels of OsIAA3 and cell elongation-related genes. Supraoptimal CK content increases ethylene level by promoting ethylene biosynthesis, which in turn inhibits rice seminal root growth by reducing root meristem size and cell length.
\end{abstract}

Keywords: cytokinin; ethylene; rice; seminal root growth; meristem size; cell elongation

\section{Introduction}

Cytokinins (CKs) are an important class of phytohormone involved in a wide range of regulatory functions during plant growth and development [1-5]. CK is widely considered to inhibit root growth in dicotyledonous plants such as Arabidopsis [6-12], a viewpoint that is supported by many previous results. For example, application of exogenous CK has been found to inhibit root growth [7], sharp increases in the levels of endogenous CK inhibited root growth in amp1 mutants [6,12], and a moderate decrease in levels of endogenous CK promoted root growth in phbphv mutants [11]. However, this viewpoint cannot explain the phenomena that a severe block in CK biosynthesis or signaling resulted in impaired root growth in Arabidopsis [13,14]. In contrast, in the monocotyledonous model plant rice, phytohormones such as auxin and ethylene exert two opposing effects on seminal root growth, whereby certain threshold levels of auxin and ethylene are required for rapid growth of the seminal root in rice, but supraoptimal contents of auxin and ethylene inhibit rice seminal root growth [15]. Up to this point, it has not been clear whether CK exerts two opposing effects on seminal root growth in rice. 
One of the primary components of root growth is cell proliferation in the root meristem zone $[4,11,16]$. The speed of root cell proliferation depends on the rate of cell division in the root meristem zone, as well as root meristem size. It has been reported that CKs play an important role in controlling root meristem size, though they have no apparent effect on the rate of cell division in the root meristem zone [17]. In Arabidopsis, SHY2/IAA3 is necessary and sufficient to mediate the action of CK on root meristem size [18]. CK-induced accumulation of SHY2/IAA3 (a repressor of auxin signaling) antagonizes auxin signaling and promotes the mitotic-to-endocycle transition in root, which in turn decreases the cell number and reduces the meristem size in Arabidopsis root [4]. An Arabidopsis mutant with a loss-of-function mutation of SHY2/IAA3, shy2-31, has a larger-than-usual meristem, whereas the shy2-2 mutant (a gain-of-function mutation of SHY2/IAA3) has a smaller meristem than the wild type [18]. Rice OsIAA3 and Arabidopsis SHY2/IAA3 have similar functions, and mOsIAA3-GR mutant rice (with a gain-of-function mutation of OsIAA3) has a shorter root length than wild-type rice [19]. However, it is not clear whether CK can control root meristem size in rice by regulating transcription of OSIAA3.

On the other hand, root growth also depends on cell elongation in the elongation zone $[4,11,16]$. A previous study found that exogenous $\mathrm{CK}$ treatment reduced the extent of cell elongation and reduced final cell length in Arabidopsis [20], suggesting that cell elongation may be negatively regulated by CK. However, it is unclear whether CK can mediate seminal root growth by regulating cell elongation in rice. It has been reported that xyloglucan endotransglucosylase/hydrolase (XTH) plays an important role in cell elongation, and there are 29 known members of the OsXTH family, which encodes these enzymes in rice [21]. Among these, OsXTH1 and OsXTH2 are specifically expressed in the root [21]. Additionally, expansin genes expressed in the roots of rice, such as OsEXP3, OsEXP13, OsEXPB4, and OsEXPB11, are associated with root cell elongation [22]. We were thus interested in determining whether CKs can mediate rice seminal root growth by mediating cell elongation via regulation of the transcription of root cell elongation-related genes.

In dicotyledonous plants, such as Arabidopsis and peas, the inhibitory effect of CK on root growth is associated with ethylene biosynthesis [7,23]. However, in monocotyledonous plants like rice, little is known about the crosstalk between CK and ethylene in the regulation of seminal root growth. The biosynthetic pathway of ethylene has been well studied [24-26]. Ethylene biosynthesis is catalyzed by the enzymes $S$-adenosyl-L-methionine synthetase (SAMS), 1-aminocyclopropane-1-carboxylic acid (ACC) synthase (ACS), and ACC oxidase (ACO) $[25,27,28]$. In rice, three SAMS genes (OsSAMS1-OsSAMS3), six ACS genes (OsACS1-OsACS6), and seven ACO genes (OsACO1-OsACO7) have been identified [26,28-30]. However, OsACS6 has no ACS activity, and OsACO6 is a pseudogene [26,29]. Transcription levels of genes in the OsSAMS, OsACS, and OsACO families are positively correlated with ethylene production. Ethylene level can be increased or decreased by upregulating or downregulating transcription levels of ethylene biosynthesis genes, such as OsSAMS1, OsACS1, and OsACO2 [31-33]. Thus, an investigation of the regulatory effects of CK on the transcription of ethylene biosynthesis genes is required to confirm whether CK can mediate rice seminal root cell elongation by regulating ethylene production.

In this study, we investigated the dose-response curves of seminal root growth inhibition by exogenous lovastatin and kinetin (KT) to confirm whether CKs exert two opposing effects on seminal root growth in rice. We also explored the inhibitory mechanism of supraoptimal CK content on rice seminal root growth.

\section{Results}

\subsection{Effects of Lovastatin and KT Treatments on Rice Seminal Root Growth}

To clarify whether CK has two opposing effects on rice seminal root growth, we investigated the dose-response curve of root growth inhibition by exogenous lovastatin (a CK biosynthetic inhibitor) and KT (a synthetic CK). As shown in Figure 1a,b, low concentrations of lovastatin (0.1 nM) and 
KT (0.0004 nM) had no apparent effect on seminal root growth, whereas higher concentrations of lovastatin $(\geq 1 \mathrm{nM})$ and $\mathrm{KT}(\geq 0.004 \mathrm{nM})$ obviously inhibited seminal root growth, with a positive correlation between concentrations of lovastatin or KT and the degree of seminal root growth inhibition. The lengths of seminal roots decreased by $3,6,64$, and $76 \%$ following treatment with 1, 10, 100, and $1000 \mathrm{nM}$ lovastatin, respectively (Figure 1a). Similarly, the lengths of seminal roots decreased by 4,14 , 24,40 , and $50 \%$ with $0.004,0.04,0.4,4$, and $40 \mathrm{nM} \mathrm{KT}$ treatments, respectively (Figure 1b). Further, as shown in Table 1, lovastatin treatments dose-dependently decreased the contents of endogenous CKs including zeatin (Z) and dihydrozeatin (DZ), whereas KT treatments dose-dependently increased KT contents in rice seminal roots. These results suggest that a certain threshold content of $\mathrm{CK}$ is required for rapid growth of rice seminal root under our experimental conditions. Consequently, decreasing or increasing CK content by lovastatin or KT treatment leads to inhibition of seminal root growth in rice seedlings.
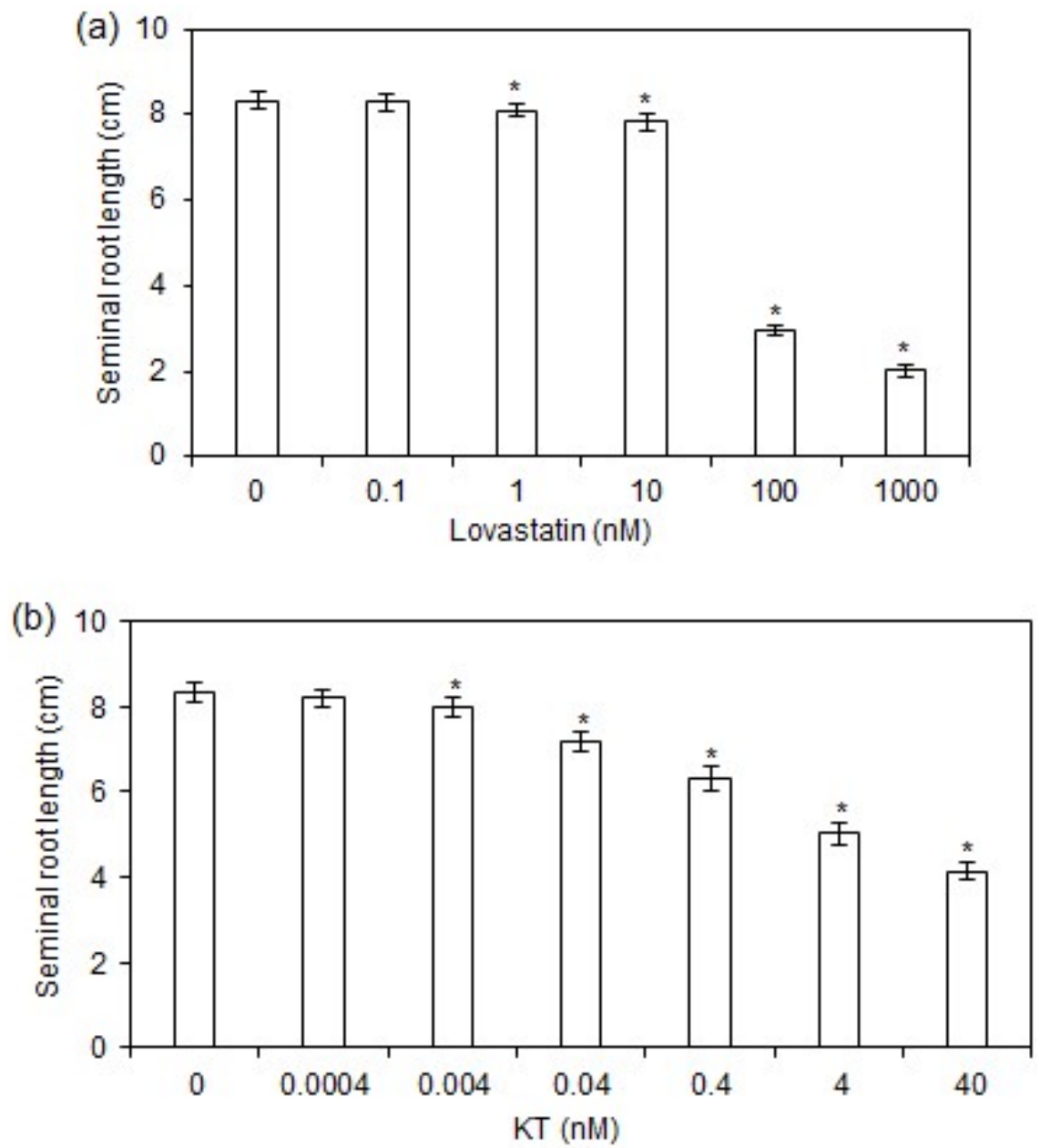

Figure 1. Dose-response curves of seminal root growth inhibition by exogenous lovastatin and kinetin (KT). Germinated rice seeds were incubated with a solution of lovastatin, KT, or distilled water as a control. The lengths of seminal roots were measured after 4 days of growth in experimental treatments. (a) Dose effects of lovastatin on rice seminal root growth. (b) Dose effects of KT on rice seminal root growth. Data are presented as means \pm standard error (SE) calculated from nine biological replicates. Asterisks indicate significant differences $(p<0.05)$ between control and experimental treatments. 
Table 1. CK content in rice seminal root under different treatments. Germinated seeds were treated with lovastatin, KT or distilled water as a control. After 4 day of treatments, CKs in rice seminal root were measured. Data are means \pm standard error (SE) of three independent biological replicates. LOV, lovastatin; KT, kinetin; Z, zeatin; DZ, dihydrozeatin; iP, isopentenyladenine; ND, below detection limits; FW, fresh weight.

\begin{tabular}{cccccc}
\hline Treatment & $\begin{array}{c}\text { KT } \\
\left.\mathbf{( n g} \cdot \mathbf{g}^{-\mathbf{1}} \mathbf{F W}\right)\end{array}$ & $\begin{array}{c}\mathbf{Z} \\
\left.\mathbf{( n g} \cdot \mathbf{g}^{-\mathbf{1}} \mathbf{F W}\right)\end{array}$ & $\begin{array}{c}\mathbf{D Z} \\
\left.\mathbf{( n g} \cdot \mathbf{g}^{-\mathbf{1}} \mathbf{F W}\right)\end{array}$ & $\begin{array}{c}\mathbf{i P} \\
\left.\mathbf{( n g} \cdot \mathbf{g}^{-\mathbf{1}} \mathbf{F W}\right)\end{array}$ & $\begin{array}{c}\text { Total } \\
\left.\mathbf{( n g} \cdot \mathbf{g}^{-\mathbf{1}} \mathbf{F W}\right)\end{array}$ \\
\hline Control & ND & $89.88 \pm 2.02$ & $2.11 \pm 0.03$ & ND & 91.99 \\
$0.1 \mathrm{nM} \mathrm{LOV}$ & ND & $88.97 \pm 0.74$ & $2.07 \pm 0.06$ & ND & 91.04 \\
1 nM LOV & ND & $84.86 \pm 1.05$ & $1.87 \pm 0.06$ & ND & 86.73 \\
10 nM LOV & ND & $61.40 \pm 1.80$ & $1.23 \pm 0.04$ & ND & 62.63 \\
100 nM LOV & ND & $43.30 \pm 1.19$ & $0.92 \pm 0.03$ & ND & 44.22 \\
1000 nM LOV & ND & $29.60 \pm 1.64$ & $0.65 \pm 0.03$ & ND & 30.25 \\
0.0004 nM KT & ND & $89.12 \pm 1.70$ & $2.11 \pm 0.08$ & ND & 91.23 \\
0.004 nM KT & $4.39 \pm 0.14$ & $89.24 \pm 0.74$ & $2.06 \pm 0.08$ & ND & 95.69 \\
0.04 nM KT & $5.95 \pm 0.12$ & $89.70 \pm 1.40$ & $2.06 \pm 0.10$ & ND & 97.71 \\
0.4 nM KT & $6.57 \pm 0.50$ & $89.95 \pm 1.30$ & $2.08 \pm 0.06$ & ND & 98.6 \\
4 nM KT & $9.82 \pm 0.26$ & $89.33 \pm 0.16$ & $2.03 \pm 0.09$ & ND & 101.18 \\
40 nM KT & $18.42 \pm 0.40$ & $89.69 \pm 0.77$ & $2.06 \pm 0.07$ & ND & 110.17 \\
\hline
\end{tabular}

\subsection{Exogenous CK Inhibited Rice Seminal Root Growth by Promoting Ethylene Production}

To investigate whether the growth-inhibitory effect of $\mathrm{CK}$ on rice seminal roots was mediated by CK-induced ethylene production, we compared seminal root lengths and ethylene production in control, KT, and KT plus aminoethoxyvinylglycine (AVG; an inhibitor of ethylene biosynthesis) treatments. The results demonstrated that the lengths of rice seminal roots were reduced by $50 \%$ in the $40 \mathrm{nM} \mathrm{KT}$ treatment, but that treatment with AVG alleviated the growth-inhibitory effect of KT treatment in a dose-dependent manner (Figure 2a). Although a low concentration ( $0.4 \mathrm{nM})$ of AVG had no apparent mitigating effect on KT-induced growth inhibition of rice seminal roots, relatively higher concentrations (2-10 nM) of AVG obviously attenuated the growth-inhibitory effect of KT, and treatment containing $50 \mathrm{nM}$ of AVG restored seminal root length in the KT treatment to that of the control (Figure 2a). This result suggests that growth inhibition of rice seminal roots caused by supraoptimal CK content might be mediated by CK-induced ethylene production. To clarify this issue, we investigated the antagonistic effects of AVG on KT-induced ethylene production in rice seminal roots. We found that ethylene production was significantly enhanced by the application of $40 \mathrm{nM}$ KT (Figure 2b), with ethylene levels 1.7 times higher in the seminal roots of KT-treated rice seedlings than in controls, while $50 \mathrm{nM}$ AVG treatment significantly inhibited KT-induced ethylene production (Figure $2 b$ ). These results indicate that supraoptimal CK content inhibits seminal root growth by inducing ethylene production. 

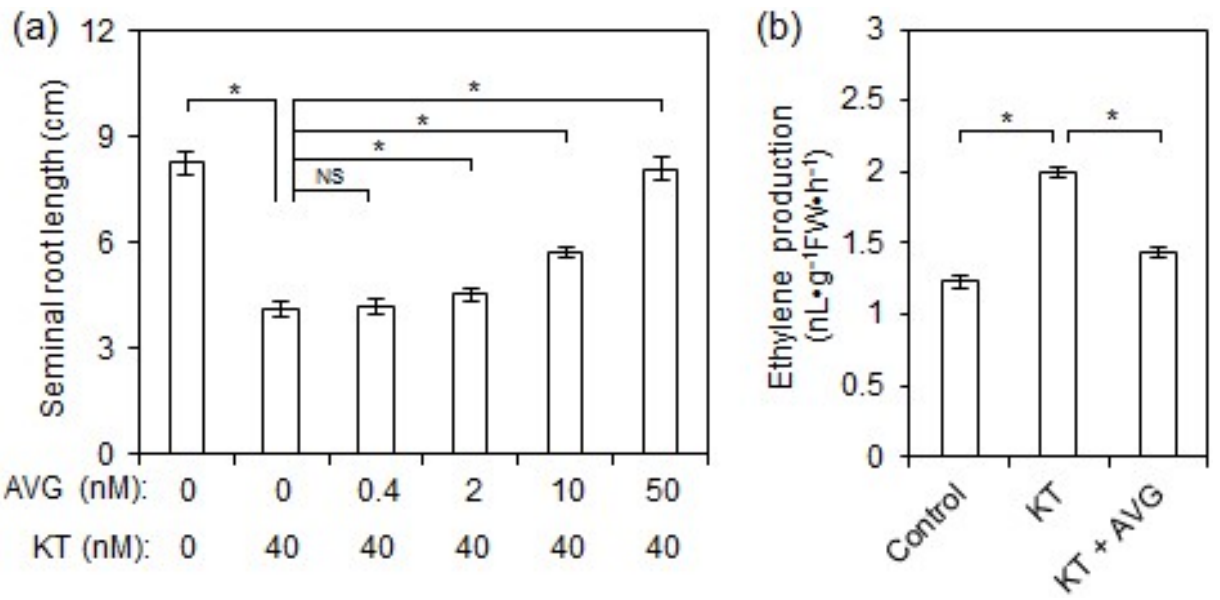

Figure 2. Mitigating effects of aminoethoxyvinylglycine (AVG) on KT-induced root growth inhibition and ethylene production in rice seminal roots. Germinated rice seeds were incubated in a solution of $\mathrm{KT}, \mathrm{KT}+\mathrm{AVG}$, or distilled water as a control. After 4 days of growth, we measured the lengths of seminal roots and the amount of ethylene produced. Seminal root length and ethylene production were calculated from nine and three biological replicates, respectively. Data are presented as means $\pm \mathrm{SE}$, and significant differences $(p<0.05)$ between various treatments are indicated by asterisks. (a) Mitigating effect of AVG on KT-induced root growth inhibition. (b) Mitigating effect of AVG on KT-induced ethylene production. KT, treatment of $40 \mathrm{nM} \mathrm{KT}$; KT + AVG, treatment of $40 \mathrm{nM}$ KT plus 50 nM AVG; FW, fresh weight. NS, no significance.

\subsection{Exogenous CK Upregulated Transcription of Ethylene Biosynthesis Genes in Rice Seminal Roots}

It has been reported that three gene families-OsSAMS, OsACS, and OsACO-are involved in ethylene biosynthesis $[25,27,29]$. We performed a time-course analysis of the expression patterns of OsSAMS, OsACS, and OsACO family genes to investigate the effects of supraoptimal CK content on ethylene biosynthesis in rice seminal roots. Transcription levels of OsSAMS genes were significantly higher in the $40 \mathrm{nM} \mathrm{KT}$ treatment and increased with the duration of KT treatment (from 1 to 4 days; Figure $3 \mathrm{a}-\mathrm{c}$ ). A single day of KT treatment induced transcription of three OsACS genes (OsACS1, OsACS3, and OsACS5), while the other two OsACS genes (OsACS2 and OsACS4) had no apparent response (Figure 3a). After 2 days of KT treatment, the transcription levels of all the OsACS genes were upregulated (Figure $3 \mathrm{~b}$ ). After 4 days of KT treatment, OsACS1 was no longer induced, though transcription of the other OsACS genes was still induced by the treatment (Figure 3c). Transcription levels of OsACO1, OsACO2, and OsACO3 were also significantly upregulated by KT treatment during the entire experimental period. The transcription level of OsACO3 increased 21.6-, 32.6-, and 20.9-fold after 1, 2, and 4 days of KT treatment, respectively (Figure 3a-c). These results indicate that in rice seminal roots, exogenous $\mathrm{CK}$ treatment induces ethylene production by upregulating the transcription of ethylene biosynthesis genes, with the strongest effect on the OsACO family genes, especially OsACO3.

\subsection{CK-Induced Ethylene Reduced Meristem Size and Cell Length of Rice Seminal Roots}

Root length is mainly determined by root meristem size and cell length $[4,11,16-18]$. To clarify whether CK-induced ethylene production reduced seminal root length by decreasing root meristem size and/or cell length, we investigated the effects of control, KT, and KT + AVG treatments on seminal root meristem size and cell length. We found that the size of seminal root meristems in the KT treatment group decreased by $26 \%$ compared with those in control conditions, but that this effect was negated by the application of AVG (Figure 4a,b). Similarly, the final lengths of cells in the differentiation zones of rice seminal roots were also significantly reduced by KT treatment, whereas KT-reduced cell length was rescued by AVG treatment (Figure 4c,d). The average root cell length was decreased by $41 \%$ in KT treatment versus the control. However, there was no significant difference in root cell length between 
the control and KT + AVG treatment. These results suggested that ethylene produced in response to supraoptimal CK content reduces seminal root length in rice seedlings by decreasing root meristem size and root cell length.
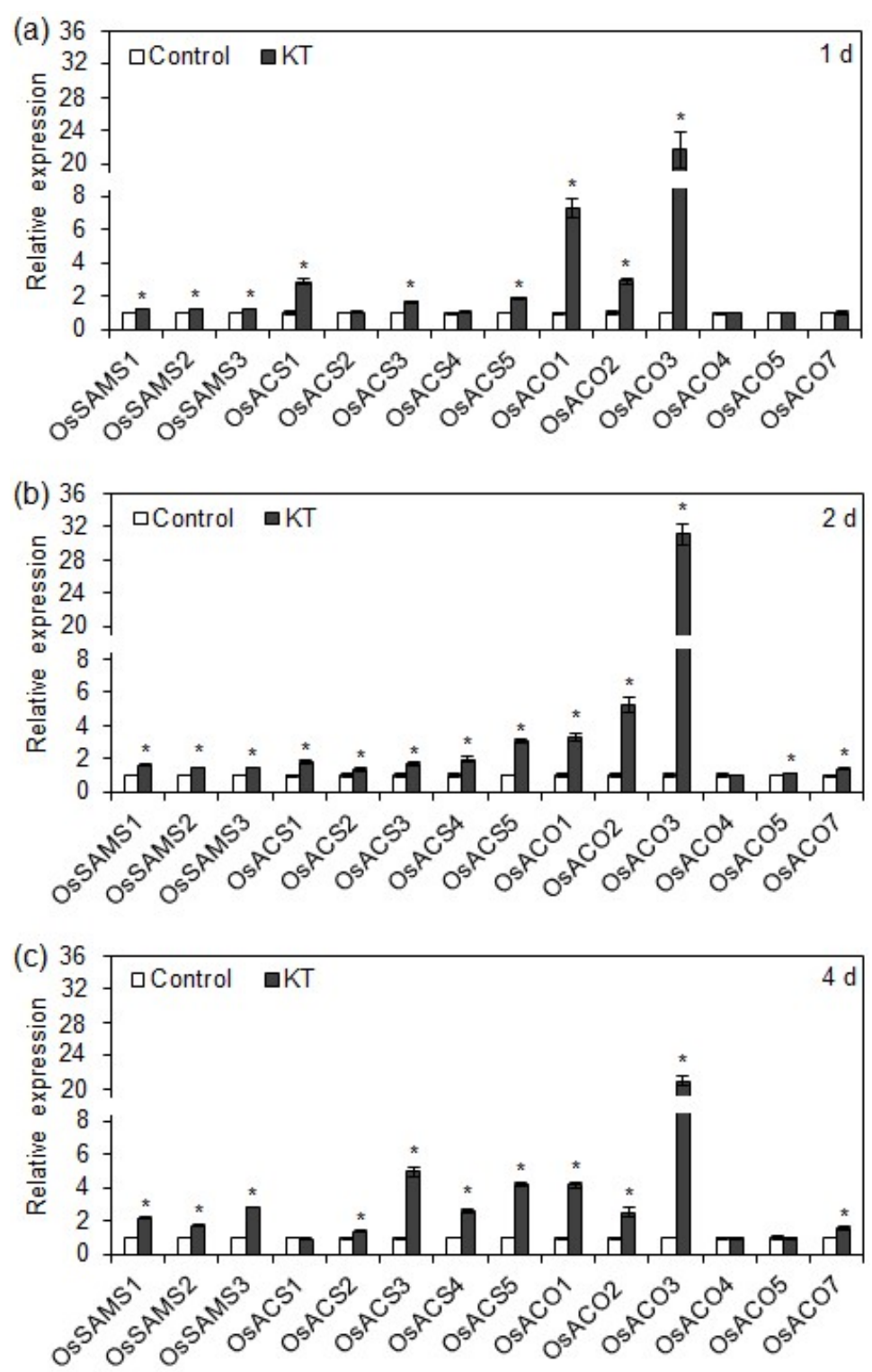

Figure 3. Transcriptional regulation by exogenous KT on ethylene biosynthesis genes in rice seminal roots. Germinated rice seeds were incubated with a solution of $40 \mathrm{nM} \mathrm{KT}$ or distilled water as a control. Seminal roots were collected for qRT-PCR (quantitative real-time PCR) analysis after 1 day (a), 2 days (b), and 4 days (c). Data are presented as means \pm SE. Three biological replicates with three technical replicates were included in the statistical analysis and error range analysis. Asterisks indicate significant differences $(p<0.05)$ in expression of the same genes in the control and KT treatment conditions. 
(a)

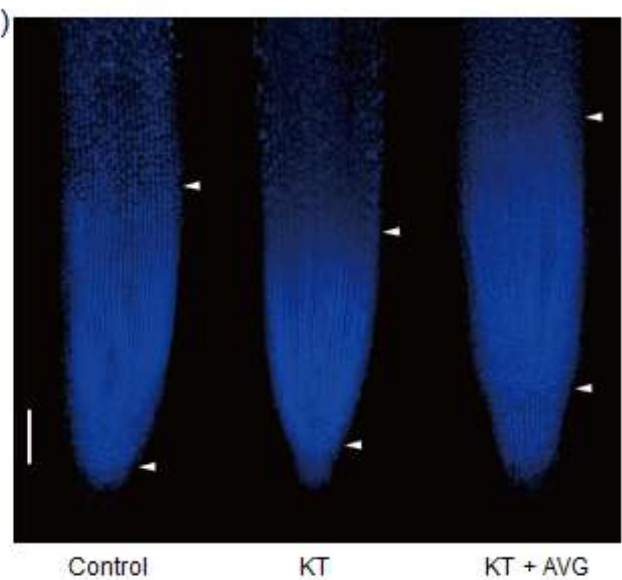

(c)

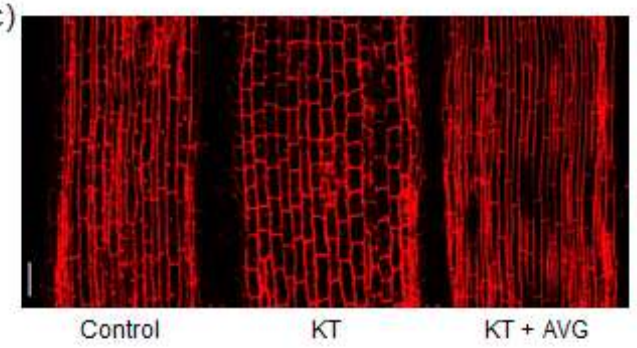

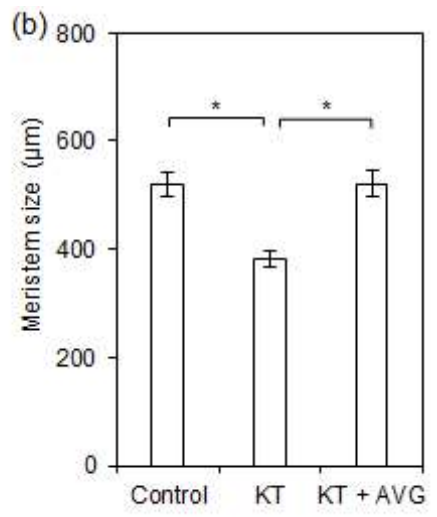

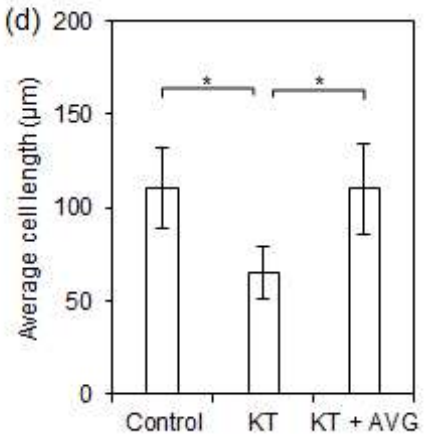

Figure 4. Mitigating effects of AVG on KT-reduced meristem size and cell length in rice seminal roots. Germinated rice seeds were incubated with a solution of KT, KT + AVG, or distilled water as a control. $(\mathbf{a}, \mathbf{b})$ Mitigating effects of AVG on KT-reduced seminal root meristem size in rice. After 4 days of growth in experimental conditions, the meristem sizes of rice seminal roots were measured using 4',6-diamidino-2-phenylindole staining. (c,d) Mitigating effects of AVG on KT-reduced cell length in the differentiation zones of rice seminal roots. After 4 days of growth in experimental conditions, the lengths of cells in the differentiation zones of rice seminal roots were measured using propidium iodide staining. Bars $=100 \mu \mathrm{m}$ for (a) and $50 \mu \mathrm{m}$ for (c). Data are presented as means $\pm \mathrm{SE}$ calculated from nine biological replicates and significant differences $(p<0.05)$ are indicated by asterisks. $\mathrm{KT}$, treatment of $40 \mathrm{nM} \mathrm{KT}$; KT + AVG, treatment of $40 \mathrm{nM} \mathrm{KT}$ plus $50 \mathrm{nM}$ AVG.

\subsection{CK-Induced Ethylene Promoted OsIAA3 Transcription and Inhibited Transcription of Cell Elongation-Related Genes in Rice Seminal Roots}

It has been reported that $S H Y 2 / I A A 3$ is both necessary and sufficient to mediate the action of CK on root meristem size in Arabidopsis, and transcription levels of $S H Y 2 / I A A 3$ are negatively correlated with root meristem size in Arabidopsis [18]. On the other hand, cell length is closely associated with transcription levels of root cell elongation-related genes, such as XTH and expansin genes [21,22]. Thus, to clarify the underlying mechanism by which CK-induced ethylene acts on root meristem size and root cell length, we investigated the effects of KT and KT + AVG treatments on the transcription of OsIAA3 and root cell-elongation related genes.

As shown in Figure 5a-c, 1, 2, and 4 days of KT treatment upregulated transcription levels of OsIAA3 1.2-, 1.5-, and 1.5-fold, respectively. However, KT-induced transcription of OsIAA3 was repressed by application of AVG. We also found that after 1 day of KT treatment, although there was no change in the transcription of OsEXP13 and OsEXPB4, the transcription levels of other root cell-elongation related genes, including OsXTH1, OsXTH2, OsEXP3, and OsEXPB11, were downregulated. All root cell-elongation related genes were significantly downregulated after 2 days of KT treatment, and most of the root cell elongation-related genes remained downregulated on day 4 of KT treatment. However, the downregulation of root cell elongation-related gene 
transcription caused by KT treatment was mitigated by the application of AVG. These results suggest that in rice seminal roots, CK-induced ethylene production causes reduced root meristem size and cell length by upregulating transcription of OSIAA3 and downregulating transcription of root cell elongation-related genes.
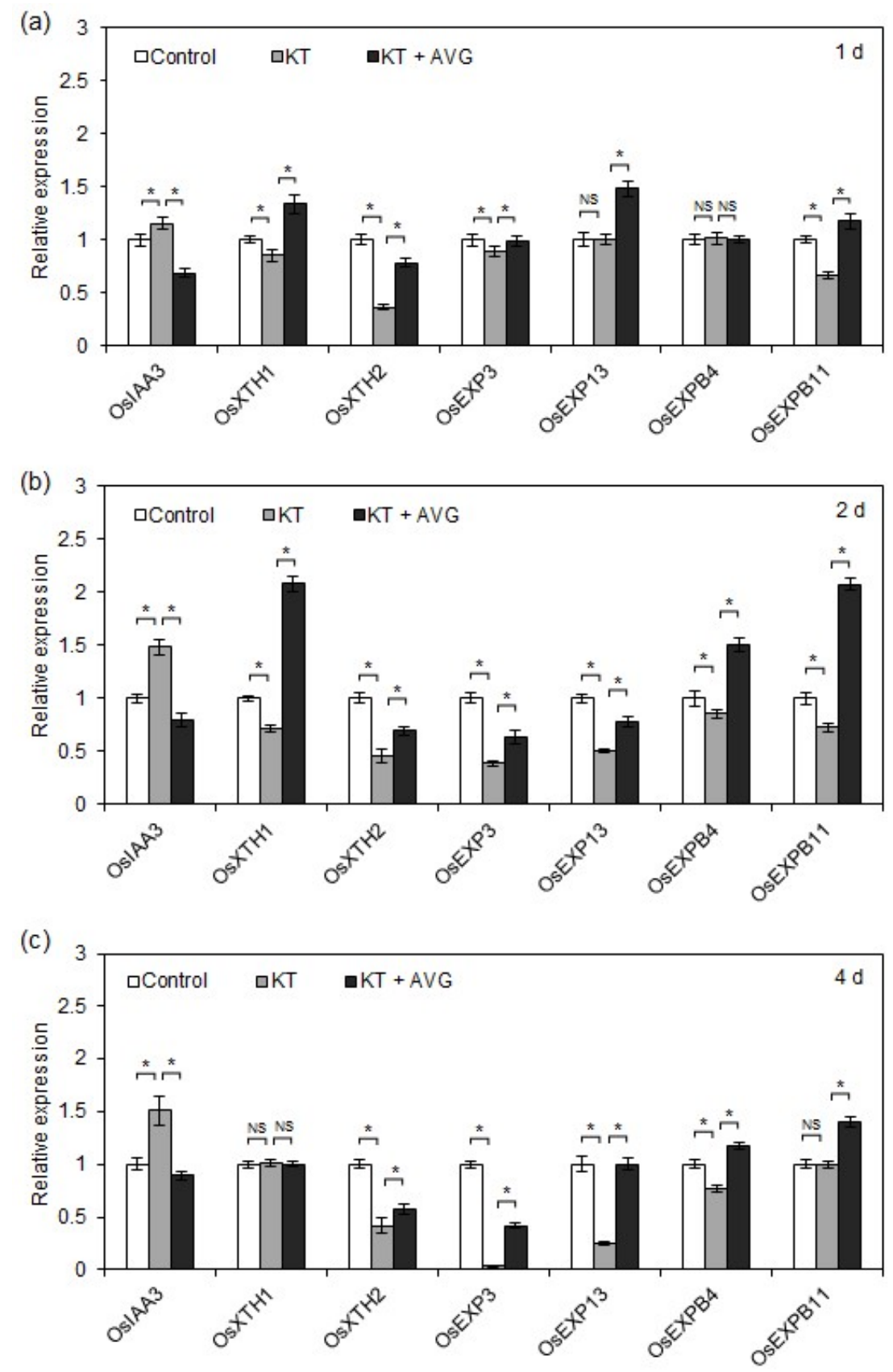

Figure 5. Mitigating effects of AVG on the upregulation of OSIAA3 and downregulation of cell elongation-related genes by exogenous KT in rice seminal roots. Germinated rice seeds were incubated with a solution of $\mathrm{KT}, \mathrm{KT}+\mathrm{AVG}$, or distilled water as a control. Rice seminal roots were collected after 1 day (a), 2 days (b), and 4 days (c) of growth and qRT-PCR was used to compare the transcription levels of OsIAA3 and cell elongation-related genes in each treatment at each time point. Data are presented as means \pm SE. Three biological replicates with three technical replicates were included in the statistical analysis and error range analysis. Significant differences $(p<0.05)$ in transcription rates of the same gene in different treatments are indicated by asterisks. KT, treatment of $40 \mathrm{nM} \mathrm{KT}$; $\mathrm{KT}+\mathrm{AVG}$, treatment of $40 \mathrm{nM}$ KT plus $50 \mathrm{nM}$ AVG. NS, no significance. 


\section{Discussion}

\subsection{Threshold Content of CK Is Required for Rapid Growth of Rice Seminal Roots}

Although low concentrations of lovastatin had no apparent effect on rice seminal root growth, high concentrations of lovastatin obviously inhibited rice seminal root growth in a dose dependent manner (Figure 1a). Moreover, KT treatment dose-dependently inhibited seminal root growth in rice (Figure 1b). Our result is consistent with previous reports in Arabidopsis that application of exogenous benzyladenine inhibited root growth in a dose-dependent manner [34]. These results suggest that a certain threshold content of $C K$ is required for rapid growth of rice seminal roots. This is consistent with previous reports that overexpression of CYTOKININ OXIDASE DEHYDROGENASE 7 (CKX7) in Arabidopsis caused a severe CK deficiency and inhibited primary root growth, and that decreases in the levels of $c$ Z-type CKs inhibited primary root growth in ipt2,9, a CK biosynthesis mutant [13]. Prior studies have also shown severely impaired root growth in CK signaling triple mutants, such as ahk2-1 ahk3-1 ahk4-1 and cre1-12 ahk2-2 ahk3-3, in which CK signaling is severely blocked [14,34]. Additionally, the overexpression of OsRR6, a negative regulator of CK signaling, has been found to result in impaired root growth [35]. It seems probable that a certain threshold content of CK in roots could stimulate cell division, and thus cell division defects in the root occur only when CK signaling is severely inhibited $[14,34,36]$. Thus, we concluded that there exists a threshold of CK content that must be reached to allow rapid growth of the seminal root in rice.

\subsection{Supraoptimal CK Content Inhibits Rice Seminal Root Growth}

Usually, phytohormones have two opposing effects on root growth, one inhibitory and one stimulatory [15]. Accordingly, although a certain threshold CK content is required for rapid root growth, supraoptimal CK content inhibits root growth [14,34,36]. Studies in Arabidopsis have suggested that endogenous CK levels may in fact be supraoptimal for primary root growth because moderate decreases in CK levels promote growth of the primary root. A moderate decrease in endogenous CK level through overexpression of $C K X$ family genes, such as $A t C K X 1$ and $A t C K X 3$, has been found to result in the promotion of primary root growth [8,9]. Likewise, the primary roots of ipt 357 and ipt 1357 mutants, in which CKs are moderately decreased, are slightly longer than those of wild-type plants [37]. Additionally, moderate attenuations in CK signaling in arr1 1012 and ahk2 ahk3 mutants leads to longer primary roots $[10,36]$. However, the results of the current study indicate that endogenous CK content might be optimal for rapid growth of the rice seminal root under our experimental conditions, and thus either a decrease or an increase in CK level leads to inhibition of rice seminal root growth (Figure $1 \mathrm{a}, \mathrm{b}$ and Table 1). A possible explanation for this difference between our result in rice and previous results in Arabidopsis is that our rice seedlings were cultured without nitrates. Nitrates can promote CK biosynthesis by inducing expression of isopentenyltransferase (IPT) genes such as IPT3 [37]. However, we cannot rule out the possibility that the difference between our result in rice and previous results in Arabidopsis is simply reflective of basic biological differences between different species.

It has been reported that IPT is a key enzyme in CK biosynthesis [37,38]. Consequently, increasing levels of endogenous CK by overexpressing IPT genes leads to inhibition of primary root growth in Arabidopsis [38]. Increased levels of endogenous CK in amp1 mutants and treatment with exogenous CK also inhibit Arabidopsis primary root growth [6,7,12,39]. Consistent with these results in Arabidopsis, our result demonstrated that application of KT, a synthetic CK, inhibited rice seminal root growth in a dose-dependent manner (Figure 1b). All of this evidence indicates that although a certain threshold content of CK is required for rapid growth of rice seminal root, supraoptimal CK content inhibits root growth, suggesting that $\mathrm{CK}$ exerts two opposing effects on rice seminal root growth. 


\subsection{Supraoptimal CK Content Inhibits Rice Seminal Root Growth by Promoting Ethylene Biosynthesis}

In this study, the application of exogenous KT to rice seedlings increased ethylene levels, which in turn inhibited rice seminal root growth (Figure 1b); however, this KT-induced inhibition of seminal root growth was completely rescued by the application of AVG (Figure 2a). Our evidence is consistent with a previous report that application of benzylaminopurine (a synthetic CK) strongly induced ethylene production in pea roots [23]. Our evidence is also supported by previous reports that ethylene is involved in CK-induced growth inhibition of Arabidopsis roots [7,23,40], and that $\mathrm{Al}^{3+}$-induced growth inhibition of bean roots is preceded by significant increase in CK ( $Z$ and DZ) levels and enhanced ethylene evolution [41]. Our results suggest that the mechanism by which supraoptimal CK content inhibits rice seminal root growth is through increased ethylene biosynthesis. However, in Arabidopsis, the inhibitory effect of CK on root growth is considered to be mainly, but not entirely, driven by CK-induced ethylene, because CK-induced root growth inhibition can be significantly (but not completely) restored by application of $\mathrm{AgNO}_{3}$ (an inhibitor of ethylene action) [7]. A possible explanation for this difference between Arabidopsis and rice is that the treatment concentration of $\mathrm{AgNO}_{3}$ on Arabidopsis plants was not optimal, and relatively low or high concentrations of $\mathrm{AgNO}_{3}$ could not completely restore CK-induced inhibition of root growth. Another possibility is that the difference is due to the different mechanisms of action of AVG and $\mathrm{AgNO}_{3}$.

Previous studies have concluded that CKs promote ethylene production in Arabidopsis mainly by upregulating the transcription level of AtACS5 [40,42,43]. By contrast, we found that supraoptimal CK content promotes ethylene biosynthesis by upregulating the transcription of ethylene biosynthesis genes, including genes from the OsSAMS, OsACS, and OsACO families. This evidence is consistent with previous reports that transcription levels of OsSAMS, OsACS, and OsACO family genes were positively correlated with ethylene production, and that ethylene levels can be increased or decreased by upregulating or downregulating transcription levels of ethylene biosynthesis genes [26,28-33]. Among the ethylene biosynthesis gene families, OsACO family genes exhibited the strongest response to the application of KT, and the transcription level of OsACO3 was upregulated more than 20-fold during the experimental period (Figure $3 \mathrm{a}-\mathrm{c}$ ). Thus, the mechanism by which supraoptimal CK content promotes ethylene biosynthesis, thereby inhibiting rice seminal root growth, appears to be via upregulated transcription levels of ethylene biosynthesis genes.

\subsection{CK-Induced Ethylene Inhibits Rice Seminal Root Growth by Reducing Meristem Size and Cell Length}

Root growth is positively controlled by root meristem size $[8,9,13,14]$. It has been reported that SHY2/IAA3 is both necessary and sufficient to mediate the action of CKs on root meristem size in Arabidopsis [18], and that rice OsIAA3 has a similar function to Arabidopsis SHY2/IAA3 [19]. Here, we have provided evidence that exogenous application of $40 \mathrm{nM} \mathrm{KT}$ strongly promoted ethylene production and significantly upregulates the transcription of OsIAA3 and reduces root meristem size, and that the regulatory effects of KT on ethylene biosynthesis, OsIAA3 transcription and root meristem size can be restored by the application of the ethylene biosynthesis inhibitor AVG (Figures 4 and 5). Root growth inhibition by CK-induced ethylene production is thus enacted via upregulated transcription of OsIAA3, causing reduced root meristem size. Our result is supported by previous reports that ethylene treatment induces the $S H Y 2 / I A A 3$ transcription and facilitates the transition from mitotic cell cycle to the endocycle, which in turn decreases the cell number and reduces the meristem size in Arabidopsis root [4,44].

Root growth is also positively correlated with cell elongation $[4,16]$. It has been reported that transcription levels of root cell elongation-related genes are positively correlated with cell elongation in rice roots [21,22]. Moreover, previous research has suggested that ethylene strongly inhibits cell elongation and reduces primary root length in Arabidopsis [16]. In this study, exogenous application of $40 \mathrm{nM}$ KT strongly promoted ethylene production and significantly downregulated the transcription of root cell elongation-related genes and reduced cell length, and the regulatory effects of KT on ethylene biosynthesis, transcription of root cell elongation-related genes, and cell length were restored 
by the application of AVG (Figures 4 and 5). This result indicates that CK-induced ethylene inhibits rice seminal root growth by reducing cell length via downregulated transcription levels of root cell elongation-related genes. Overall, CK-induced ethylene inhibits rice seminal root growth by reducing root meristem size and cell length.

\section{Materials and Methods}

\subsection{Plant Material and Growth Conditions}

We used seeds of indica rice 9311 (Oryza sativa L.) in this study. Rice 9311 is a high-quality inbred variety widely used in China [45]. Seeds were sterilized, soaked, and germinated according to Yin et al. [15]. Rice 9311 seeds were surface sterilized in a solution of $5 \%(v / v) \mathrm{NaOCl}$ for $20 \mathrm{~min}$, rinsed six times with distilled water, and then soaked in distilled water for 1 day at $26^{\circ} \mathrm{C}$. Subsequently, rice seeds were germinated for another day at $26^{\circ} \mathrm{C}$, and then the germinated seeds were incubated on plastic screens floating on different treatment solutions. Rice seedlings were grown in an artificial climate incubator (HP 1500 GS-B) with a 12 -h light $\left(29^{\circ} \mathrm{C}\right) / 12$-h dark $\left(26^{\circ} \mathrm{C}\right)$ photoperiod.

\subsection{Chemicals and Treatments}

Kinetin (KT), lovastatin, and aminoethoxyvinylglycine (AVG) were purchased from Sigma-Aldrich Trading Co., Ltd. (Shanghai, China). Each chemical was dissolved in dimethyl sulfoxide (DMSO) and diluted to the required concentration with distilled water. The $\mathrm{pH}$ of all treatment solutions was adjusted to 6.5 , and all solutions had the same concentration of DMSO $(0.01 \% v / v)$. KT was used as a synthetic CK, lovastatin was used as a CK biosynthesis inhibitor [46-48], and AVG was used as an ethylene biosynthesis inhibitor $[15,49,50]$. Germinated seeds were incubated in one of these solutions or in distilled water as a control. All treatment solutions were refreshed every 2 days.

\subsection{Ethylene Production Measurements}

The ethylene produced by rice seminal roots was measured as previously described [51]. In short, after 4 days of growth in experimental conditions, intact roots were detached from rice seedlings and placed into 50-mL airtight glass vials with $1 \mathrm{~mL}$ distilled water and allowed to stand for $5 \mathrm{~h}$. A 3-mL gas sample was withdrawn by gas-tight syringe from the airspace of each vial and ethylene content was detected by gas chromatography (Varian CP-3800, Agilent Corporation, Santa Clara, CA, USA). Data are presented as the means \pm standard error (SE) calculated from three biological replicates.

\subsection{Extraction, Purification and Quantification of CKs}

The germinated seeds were treated with lovastatin, KT or distilled water as a control. After 4 days of treatments, the seminal roots of rice seedlings were collected and frozen at $-80{ }^{\circ} \mathrm{C}$ until use. Extraction, purification and quantification of CKs were performed according to the method described previously [52]. Each sample was ground to a fine power in liquid nitrogen, weighed ( $100 \mathrm{mg}$ for each sample) and put into a 1.5-mL tube, mixed with $750 \mu \mathrm{L}$ cold extraction buffer (methanol:wateracetic acid, 80:19:1, $v / v / v$ ), shaken on a shaking bed for $16 \mathrm{~h}$ at $4{ }^{\circ} \mathrm{C}$ in dark, and then centrifuged at $13,000 \mathrm{rpm}$ for $15 \mathrm{~min}$ at $4{ }^{\circ} \mathrm{C}$. The supernatant was transferred to a new $1.5-\mathrm{mL}$ tube and the pellet was remixed with $400 \mu \mathrm{L}$ extraction buffer, shaken for $4 \mathrm{~h}$ at $4{ }^{\circ} \mathrm{C}$, and centrifuged. The two supernatants were combined and filtered using a syringe-facilitated 13-mm diameter nylon filter with pore size $0.22 \mu \mathrm{m}$. The filtrate was dried by evaporation under the flow of nitrogen gas at room temperature, and then dissolved in $200 \mu \mathrm{L}$ methanol. Subsequently, the predominant CKs (Z, DZ, and $\mathrm{iP}$ ) found in higher plants, and KT was quantified using an acquity UPLC H-Class Xevo G2-XS (Waters Corporation, Milford, MA, USA). Data are means \pm standard error (SE) of three independent biological replicates. 


\subsection{RNA Isolation and $q R T-P C R$ Analysis}

Total RNA was extracted according to Liu et al. [53]. Total RNA was extracted from rice seminal root tips using the RNAprep Pure Plant Kit (Tiangen Biotech, Beijing, China) according to the manufacturer's instructions, and first-strand cDNA was synthesized using the FastKing RT Kit (Tiangen Biotech Corporation, Beijing, China). The gene-specific primers listed in Supplementary Table S1 were used to analyze the relative expressions of all genes by qRT-PCR. The relative expression of the target gene was calculated with the comparative threshold method, using OSACTIN as an internal control. Data are presented as means $\pm \mathrm{SE}$, using three biological replicates with three technical replicates for statistical analyses and error range analyses.

\subsection{Examination of Root Meristem Size and Cell length}

Rice seedlings were treated with various solutions for 4 days. For meristem size measurement, root tips were stained with 4',6-diamidino-2-phenylindole solution for $5 \mathrm{~min}$, washed three times with distilled water, and visualized with a confocal microscope (Leica SP8, Leica Corporation, Solms, Germany). For cell length measurement, the differentiation zones of the rice seminal roots were stained with propidium iodide as previously described [44,54], washed three times with distilled water, and visualized with a confocal microscope (Leica SP8). Meristem size and cell length were measured using Image software (National Institutes of Health, Bethesda, MD, USA). The data are presented as means \pm SE calculated from nine biological replicates.

\subsection{Statistical Analyses}

Statistical analysis was performed using an independent samples $t$-test, or a one-way analysis of variance followed by Duncan's multiple range test with at least three replicates. The threshold for significance was set at $p<0.05$. All data are presented as means \pm SE.

\section{Conclusions}

Our results suggest that $\mathrm{CK}$ has two opposing effects on rice seminal root growth. A certain threshold content of CK is required for rapid growth of rice seminal roots, but this growth is inhibited by a supraoptimal CK content. Further, we have provided evidence that supraoptimal CK content increases ethylene level by upregulating transcription levels of ethylene biosynthesis genes, which in turn inhibits rice seminal root growth by reducing root meristem size and cell length via upregulation of OsIAA3 transcription and downregulation of cell elongation-related genes transcription, respectively.

Supplementary Materials: Supplementary materials can be found at http:/ / www.mdpi.com/1422-0067/19/12/ 4051/s1.

Author Contributions: Conceptualization, C.Y.; methodology, C.Y., X.Z. and J.S.; software, X.Z. and J.S.; validation, C.Y., X.Z. and J.S.; formal analysis, X.Z.; investigation, X.Z., J.S., Q.W., P.C., Y.Z.; resources, C.Y.; data curation, X.Z. and J.S.; writing-original draft preparation, X.Z. and J.S.; writing-review and editing, X.Z., C.Y., Q.W., P.C. and Y.Z.; visualization, X.Z. and J.S.; supervision, C.Y.; project administration, C.Y.; funding acquisition, C.Y.

Funding: This research was funded by The National Key Research and Development Program of China (No. 2016YFD0300102), The Natural Science Foundation of Hubei Province of China (No. 2016CFB436), China Postdoctoral Science Foundation (Nos. 2015M580652 and 2016T90705), and The Fundamental Research Funds for the Central Universities (No. 2662018PY076).

Acknowledgments: We are grateful to Yongjun Lin (Huazhong Agricultural University, Wuhan, China) for critical reading of the manuscript. We thank Youjia Shen (Nanjing Agricultural University, Nanjing, China) for providing rice 9311 seeds.

Conflicts of Interest: The authors declare no conflict of interest. 


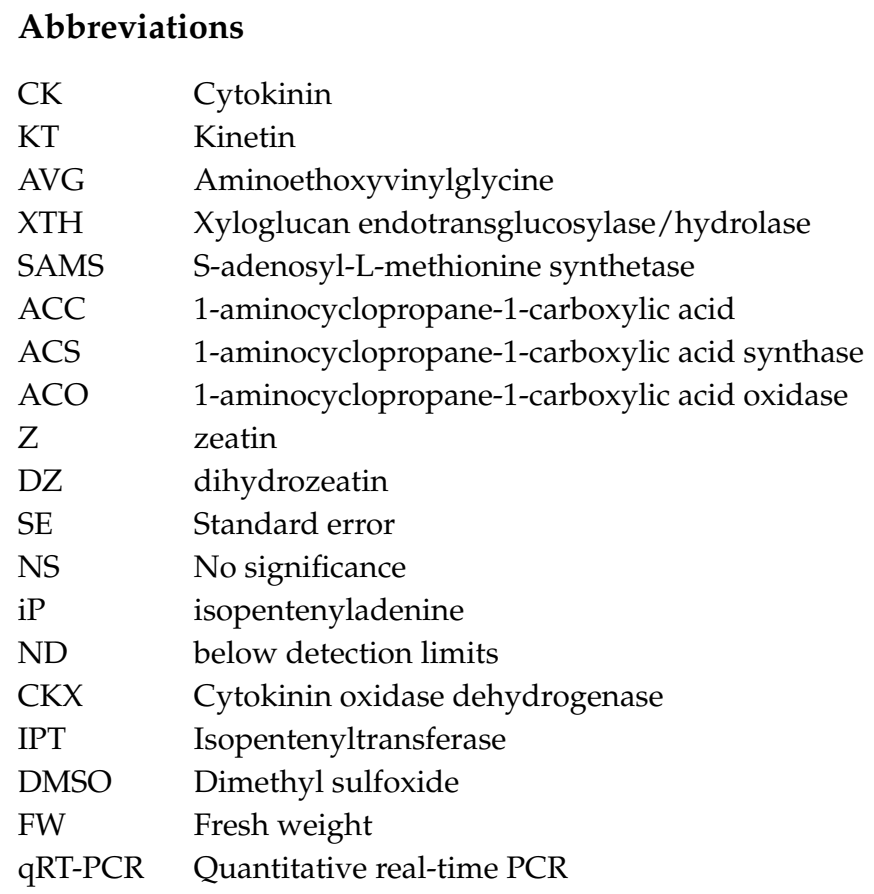

\section{References}

1. Hopping, M.E. Effect of exogenous auxins, gibberellins, and cytokinins on fruit development in Chinese gooseberry (Actinidia chinensis Planch.). N. Z. J. Bot. 1976, 14, 69-75. [CrossRef]

2. Miyoshi, K.; Sato, T. The effects of kinetin and gibberellin on the germination of dehusked seeds of indica and japonica rice (Oryza sativa L.) under anaerobic and aerobic conditions. Ann. Bot. 1997, 80, 479-483. [CrossRef]

3. Müller, D.; Leyser, O. Auxin, cytokinin and the control of shoot branching. Ann. Bot. 2011, 107, 1203-1212. [CrossRef] [PubMed]

4. Takatsuka, H.; Umeda, M. Hormonal control of cell division and elongation along differentiation trajectories in roots. J. Exp. Bot. 2014, 65, 2633-2643. [CrossRef] [PubMed]

5. Liu, L.; Li, H.; Zeng, H.; Cai, Q.; Zhou, X.; Yin, C. Exogenous jasmonic acid and cytokinin antagonistically regulate rice flag leaf senescence by mediating chlorophyll degradation, membrane deterioration, and senescence-associated genes expression. J. Plant Growth Regul. 2016, 35, 1-11. [CrossRef]

6. Chaudhury, A.M.; Letham, S.; Craig, S.; Dennis, E.S. amp1-A mutant with high cytokinin levels and altered embryonic pattern, faster vegetative growth, constitutive photomorphogenesis and precocious flowering. Plant J. 1993, 4, 907-916. [CrossRef]

7. Cary, A.J.; Liu, W.; Howell, S.H. Cytokinin action is coupled to ethylene in its effects on the inhibition of root and hypocotyl elongation in Arabidopsis thaliana seedlings. Plant Physiol. 1995, 107, 1075-1082. [CrossRef]

8. Werner, T.; Motyka, V.; Strnad, M.; Schmülling, T. Regulation of plant growth by cytokinin. Proc. Natl. Acad. Sci. USA 2001, 98, 10487-10492. [CrossRef]

9. Werner, T.; Motyka, V.; Laucou, V.; Smets, R.; Onckelen, H.V.; Schmülling, T. Cytokinin-deficient transgenic Arabidopsis plants show multiple developmental alterations indicating opposite functions of cytokinins in the regulation of shoot and root meristem activity. Plant Cell 2003, 15, 2532-2550. [CrossRef]

10. Riefler, M.; Novak, O.; Strnad, M.; Schmülling, T. Arabidopsis cytokinin receptor mutants reveal functions in shoot growth, leaf senescence, seed size, germination, root development, and cytokinin metabolism. Plant Cell 2006, 18, 40-54. [CrossRef]

11. Ioio, R.D.; Galinha, C.; Fletcher, A.G.; Grigg, S.P.; Molnar, A.; Willemsen, V.; Scheres, B.; Sabatini, S.; Baulcombe, D.; Maini, P.K. A PHABULOSA/cytokinin feedback loop controls root growth in Arabidopsis. Curr. Biol. 2012, 22, 1699-1704. [CrossRef] 
12. López-García, C.M.; Raya-González, J.; López-Bucio, J.S.; Guevara-García, Á.A.; López-Bucio, J. ALTERED MERISTEM PROGRAM 1 plays a role in seed coat development, root growth, and post-embryonic epidermal cell elongation in Arabidopsis. J. Plant Growth Regul. 2016, 35, 1-18. [CrossRef]

13. Köllmer, I.; Novák, O.; Strnad, M.; Schmülling, T.; Werner, T. Overexpression of the cytosolic cytokinin oxidase/dehydrogenase (CKX7) from Arabidopsis causes specific changes in root growth and xylem differentiation. Plant J. 2014, 78, 359-371. [CrossRef]

14. Nishimura, C.; Ohashi, Y.; Sato, S.; Kato, T.; Tabata, S.; Ueguchi, C. Histidine kinase homologs that act as cytokinin receptors possess overlapping functions in the regulation of shoot and root growth in Arabidopsis. Plant Cell 2004, 16, 1365-1377. [CrossRef] [PubMed]

15. Yin, C.; Wu, Q.; Zeng, H.; Xia, K.; Xu, J.; Li, R. Endogenous auxin is required but supraoptimal for rapid growth of rice (Oryza sativa L.) seminal roots, and auxin inhibition of rice seminal root growth is not caused by ethylene. J. Plant Growth Regul. 2011, 30, 20-29. [CrossRef]

16. Ri̊zicka, K.; Ljung, K.; Vanneste, S.; Podhorská, R.; Beeckman, T.; Friml, J.; Benková, E. Ethylene regulates root growth through effects on auxin biosynthesis and transport-dependent auxin distribution. Plant Cell 2007, 19, 2197-2212. [CrossRef] [PubMed]

17. Ioio, R.D.; Linhares, F.S.; Scacchi, E.; Casamitjana-Martinez, E.; Heidstra, R.; Costantino, P.; Sabatini, S. Cytokinins determine Arabidopsis root-meristem size by controlling cell differentiation. Curr. Biol. 2007, 17, 678-682. [CrossRef] [PubMed]

18. Dello, I.R.; Nakamura, K.; Moubayidin, L.; Perilli, S.; Taniguchi, M.; Morita, M.T.; Aoyama, T.; Costantino, P.; Sabatini, S. A genetic framework for the control of cell division and differentiation in the root meristem. Science 2008, 322, 1380-1384. [CrossRef]

19. Nakamura, A.; Umemura, I.; Gomi, K.; Hasegawa, Y.; Kitano, H.; Sazuka, T.; Matsuoka, M. Production and characterization of auxin-insensitive rice by overexpression of a mutagenized rice IAA protein. Plant J. 2006, 46, 297-306. [CrossRef]

20. Beemster, G.T.; Baskin, T.I. Stunted plant 1 mediates effects of cytokinin, but not of auxin, on cell division and expansion in the root of Arabidopsis. Plant Physiol. 2000, 124, 1718-1727. [CrossRef]

21. Yokoyama, R. A surprising diversity and abundance of xyloglucan endotransglucosylase/hydrolases in rice. Classification and expression analysis. Plant Physiol. 2004, 134, 1088-1099. [CrossRef] [PubMed]

22. Yi, L.; Kende, H. Expression of $\alpha$-expansin and expansin-like genes in deepwater rice. Plant Physiol. 2002, 130, 1396-1405. [CrossRef]

23. Bertell, G.; Eliasson, L. Cytokinin effects on root growth and possible interactions with ethylene and indolecetic acid. Physiol. Plantarum 1992, 84, 255-261. [CrossRef]

24. Kende, H. Ethylene biosynthesis. Annu. Rev. Plant Physiol. Plant Mol. Biol. 1993, 344, 283-307. [CrossRef]

25. Wang, K.L.; Li, H.; Ecker, J.R. Ethylene biosynthesis and signaling networks. Plant Cell 2002, 14, S131-S151. [CrossRef]

26. Rzewuski, G.; Sauter, M. Ethylene biosynthesis and signaling in rice. Plant Sci. 2008, 175, 32-42. [CrossRef]

27. Yamagami, T.; Tsuchisaka, A.; Yamada, K.; Haddon, W.F.; Harden, L.A.; Theologis, A. Biochemical diversity among the 1-amino-cyclopropane-1-carboxylate synthase isozymes encoded by the Arabidopsis gene family. J. Biol. Chem. 2003, 278, 49102-49112. [CrossRef]

28. Iwai, T.; Miyasaka, A.; Seo, S.; Ohashi, Y. Contribution of ethylene biosynthesis for resistance to blast fungus infection in young rice plants. Plant Physiol. 2006, 142, 1202-1215. [CrossRef]

29. Lee, J.H.; Chae, H.S.; Lee, J.H.; Hwang, B.; Hahn, K.W.; Kang, B.G.; Kim, W.T. Structure and expression of two cDNAs encoding S-adenosyl-L-methionine synthetase of rice (Oryza sativa L.). BBA-Gene Struct. Expr. 1997, 1354, 13-18. [CrossRef]

30. Li, W.; Han, Y.; Tao, F.; Chong, K. Knockdown of SAMS genes encoding S-adenosyl-1-methionine synthetases causes methylation alterations of DNAs and histones and leads to late flowering in rice. J. Plant Physiol. 2011, 168, 1837-1843. [CrossRef]

31. Chae, H.S.; Cho, Y.G.; Park, M.Y.; Lee, M.C.; Eun, M.Y.; Kang, B.G.; Kim, W.T. Hormonal cross-talk between auxin and ethylene differentially regulates the expression of two members of the 1-aminocyclopropane-1-carboxylate oxidase gene family in rice (Oryza sativa L.). Plant Cell Physiol. 2000, 41, 354-362. [CrossRef] [PubMed] 
32. Chen, Y.; Xu, Y.; Luo, W.; Li, W.; Chen, N.; Zhang, D.; Chong, K. The F-box protein OsFBK12 targets OsSAMS1 for degradation and affects pleiotropic phenotypes, including leaf senescence, in rice. Plant Physiol. 2013, 163, 1673-1685. [CrossRef] [PubMed]

33. Yamauchi, T.; Shiono, K.; Nagano, M.; Fukazawa, A.; Ando, M.; Takamure, I.; Mori, H.; Nishizawa, N.K.; Kawai-Yamada, M.; Tsutsumi, N.; et al. Ethylene biosynthesis is promoted by very-long-chain fatty acids during lysigenous aerenchyma formation in rice roots. Plant Physiol. 2015, 169, 180-193. [CrossRef] [PubMed]

34. Higuchi, M.; Pischke, M.S.; Mähönen, A.P.; Miyawaki, K.; Hashimoto, Y.; Seki, M.; Kobayashi, M.; Shinozaki, K.; Kato, T.; Tabata, S.; et al. In planta functions of the Arabidopsis cytokinin receptor family. Proc. Natl. Acad. Sci. USA 2004, 101, 8821-8826. [CrossRef] [PubMed]

35. Hirose, N.; Makita, N.; Kojima, M.; Kamada-Nobusada, T.; Sakakibara, H. Overexpression of a type-A response regulator alters rice morphology and cytokinin metabolism. Plant Cell Physiol. 2007, 48, 523-539. [CrossRef]

36. Mason, M.G.; Mathews, D.E.; Argyros, D.A.; Maxwell, B.B.; Kieber, J.J.; Alonso, J.M.; Ecker, J.R.; Schaller, G.E. Multiple type-B response regulators mediate cytokinin signal transduction in Arabidopsis. Plant Cell 2005, 17, 3007-3718. [CrossRef] [PubMed]

37. Miyawaki, K.; Tarkowski, P.; Matsumotokitano, M.; Kato, T.; Sato, S.; Tarkowska, D.; Tabata, S.; Sandberg, G.; Kakimoto, T. Roles of Arabidopsis ATP/ADP isopentenyltransferases and tRNA isopentenyltransferases in cytokinin biosynthesis. Proc. Natl. Acad. Sci. USA 2006, 103, 16598-16603. [CrossRef]

38. Sakamoto, T.; Sakakibara, H.; Kojima, M.; Yamamoto, Y.; Nagasaki, H.; Inukai, Y.; Sato, Y.; Matsuoka, M. Ectopic expression of KNOTTED1-like homeobox protein induces expression of cytokinin biosynthesis genes in rice. Plant Physiol. 2006, 142, 54-62. [CrossRef] [PubMed]

39. Su, W.; Howell, S.H. The effects of cytokinin and light on hypocotyl elongation in Arabidopsis seedlings are independent and additive. Plant Physiol. 1995, 108, 1423-1430. [CrossRef] [PubMed]

40. Vogel, J.P.; Woeste, K.E.; Theologis, A.; Kieber, J.J. Recessive and dominant mutations in the ethylene biosynthetic gene ACS5 of Arabidopsis confer cytokinin insensitivity and ethylene overproduction, respectively. Proc. Natl. Acad. Sci. USA 1998, 95, 4766-4771. [CrossRef]

41. Massot, N.; Nicander, B.; Barceló, J.; Poschenrieder, Ch.; Tillberg, E. A rapid increase in cytokinin levels and enhanced ethylene evolution precede $\mathrm{Al}^{3+}$-induced inhibition of root growth in bean seedlings (Phaseolus vulgaris L.). Plant Growth Regul. 2002, 37, 105-112. [CrossRef]

42. Chae, H.S.; Faure, F.; Kieber, J.J. The eto1, eto2, and eto3 mutations and cytokinin treatment increase ethylene biosynthesis in Arabidopsis by increasing the stability of ACS protein. Plant Cell 2003, 15, 545-559. [CrossRef] [PubMed]

43. Hansen, M.; Chae, H.S.; Kieber, J.J. Regulation of ACS protein stability by cytokinin and brassinosteroid. Plant J. 2009, 57, 606-614. [CrossRef] [PubMed]

44. Street, I.H.; Aman, S.; Zubo, Y.; Ramzan, A.; Wang, X.; Shakeel, S.N.; Kieber, J.J.; Schaller, G.E. Ethylene inhibits cell proliferation of the Arabidopsis root meristem. Plant Physiol. 2015, 169, 338-350. [CrossRef] [PubMed]

45. Zou, Z.; Zou, X.; Zhao, S.; Xia, C.; Qian, K.; Wang, P.; Yin, C. Fluridone induces leaf bleaching by inhibiting pigment biosynthesis via downregulated transcription levels of pigment biosynthetic genes in rice (Oryza sativa, L.). J. Plant Growth Regul. 2018, 37, 1385-1395. [CrossRef]

46. Crowell, D.N.; Salaz, M.S. Inhibition of growth of cultured tobacco cells at low concentrations of lovastatin is reversed by cytokinin. Plant Physiol. 1992, 100, 2090-2095. [CrossRef] [PubMed]

47. Miyazawa, Y.; Kato, H.; Muranaka, T.; Yoshida, S. Amyloplast formation in cultured tobacco BY-2 cells requires a high cytokinin content. Plant Cell Physiol. 2002, 43, 1534-1541. [CrossRef]

48. Hartig, K.; Beck, E. Assessment of lovastatin application as tool in probing cytokinin-mediated cell cycle regulation. Physiol. Plantarum 2005, 125, 260-267. [CrossRef]

49. Yang, S.F.; Hoffman, N.E. Ethylene biosynthesis and its regulation in higher plants. Annu. Rev. Plant Physiol. 1984, 35, 155-189. [CrossRef]

50. Chi, G.; Pua, E.; Gph, C. Role of Ethylene on de Novo shoot regeneration from cotyledonary explants of Brassica campestris ssp. pekinensis (Lour) olsson in Vitro. Plant Physiol. 1991, 96, 178-183. [CrossRef]

51. Lim, T.; Chitra, T.R.; Han, P.; Pua, E.C.; Yu, H. Cloning and characterization of Arabidopsis and Brassica juncea flavin-containing amine oxidases. J. Exp. Bot. 2006, 22, 1-15. [CrossRef] [PubMed] 
52. Liu, H.; Li, X.; Xiao, J.; Wang, S. A convenient method for simultaneous quantification of multiple phytohormones and metabolites: Application in study of rice-bacterium interaction. Plant Methods 2012, 8, 2. [CrossRef] [PubMed]

53. Liu, L.; Xia, W.; Li, H.; Zeng, H.; Wei, B.; Han, S.; Yin, C. Salinity inhibits rice seed germination by reducing $\alpha$-amylase activity via decreased bioactive gibberellin content. Front. Plant Sci. 2018, 9, 275. [CrossRef] [PubMed]

54. Thomann, A.; Lechner, E.; Hansen, M.; Dumbliauskas, E.; Parmentier, Y.; Kieber, J.; Scheres, B.; Genschik, P. Arabidopsis CULLIN3 genes regulate primary root growth and patterning by ethylene-dependent and -independent mechanism. PLoS Genet. 2009, 5, e1000328. [CrossRef] [PubMed]

2018 by the authors. Licensee MDPI, Basel, Switzerland. This article is an open access article distributed under the terms and conditions of the Creative Commons Attribution (CC BY) license (http://creativecommons.org/licenses/by/4.0/). 